\title{
Safety and tolerability of monthly galcanezumab injections in patients with migraine: integrated results from migraine clinical studies
}

Mark E. Bangs ${ }^{1}$, David Kudrow ${ }^{2}$, Shufang Wang ${ }^{1}$, Tina M. Oakes ${ }^{1}$, Gisela M. Terwindt ${ }^{3}$, Delphine Magis ${ }^{4}$, Laura Yunes-Medina ${ }^{1}$ and Virginia L. Stauffer ${ }^{1 *}$

\begin{abstract}
Background: Galcanezumab, a humanized monoclonal antibody that selectively binds to calcitonin gene-related peptide, has demonstrated a significant reduction in monthly migraine headache days in phase 2 and 3 trials. In these analyses, we aimed to evaluate the safety and tolerability of galcanezumab compared with placebo for prevention of episodic or chronic migraine.

Methods: Data were integrated from three double-blind clinical studies for the up to 6-month galcanezumab exposure group ( $N=1435)$, and from five clinical studies for the up to 1-year all-galcanezumab exposure group $(\mathrm{N}=2276)$. Patients received a monthly $120 \mathrm{mg}$ subcutaneous injection of galcanezumab (with a $240 \mathrm{mg}$ loading dose in month 1), $240 \mathrm{mg}$ galcanezumab, or placebo. Outcomes measured were treatment-emergent adverse events (TEAEs), serious AEs (SAEs), and discontinuation due to AEs (DCAEs). Laboratory results, vital signs, electrocardiogram (ECG), suicidal ideation and behavior results were evaluated.

Results: TEAEs that occurred more frequently in galcanezumab-treated patients included injection site pain, injection site reactions excluding pain, constipation, vertigo, and pruritus. The proportion of DCAEs among galcanezumab-treated patients ranged between 1.8 and 3.0\%, and differed from placebo group for galcanezumab $240 \mathrm{mg}(P<0.05)$. Fewer than $2.0 \%$ of patients in either galcanezumab dose-group compared with $1.0 \%$ of placebo-treated patients reported a SAE. There were no clinically meaningful differences between galcanezumab and placebo in laboratory measures, vital signs including blood pressure, ECGs, cardiovascular-related AEs, or suicidal ideation and behavior.
\end{abstract}

Conclusions: Galcanezumab demonstrated a favorable safety and tolerability profile for up to 1 year of treatment for the prevention of migraine.

Trial registration: Clinical Trials CGAB $=$ NCT02163993, EVOLVE-1 $=$ NCT02614183, EVOLVE-2 $=$ NCT02614196, REGAIN = NCT02614261, and CGAJ = NCT02614287. All were first posted on 25 November 2015, except CGAB posted on 16 June 2014, and before enrolling the first patient.

Keywords: CGRP, Galcanezumab, Migraine, Safety, Tolerability

\footnotetext{
*Correspondence: vstauffer@lilly.com; stauffer_virginia@lilly.com

${ }^{1}$ Eli Lilly and Company, Lilly Corporate Center, Indianapolis, IN 46285, USA

Full list of author information is available at the end of the article
}

(c) The Author(s). 2020 Open Access This article is distributed under the terms of the Creative Commons Attribution 4.0 International License (http://creativecommons.org/licenses/by/4.0/), which permits unrestricted use, distribution, and reproduction in any medium, provided you give appropriate credit to the original author(s) and the source, provide a link to the Creative Commons license, and indicate if changes were made. The Creative Commons Public Domain Dedication waiver (http://creativecommons.org/publicdomain/zero/1.0/) applies to the data made available in this article, unless otherwise stated. 


\section{Background}

Calcitonin gene-related peptide (CGRP), found in a variety of anatomical locations, has a diverse role, and evidence of its presence during migraine attacks has been established [1-4]. It facilitates the production and secretion of pro-inflammatory mediators, and its role in the pathophysiology of pain is widely recognized $[5,6]$.

CGRP is a potent microvascular vasodilator with various physiological roles [7]; therefore, specific concerns exist regarding a potential CGRP antagonism associated with hemodynamic or other cardiovascular (CV)-related adverse events (AEs) [8]. CV comorbidities, such as hypertension, and risk of ischemic CV events like stroke, myocardial infarction and heart disease are increased in the migraine population compared with nonmigraine populations [9-14]. The relationship between migraine and CV disease is still not fully understood and needs further attention; underlying pathophysiological mechanisms may play a role such as increased vascular vulnerability [8].

Galcanezumab is a humanized monoclonal antibody that is approved for the preventive treatment of migraine and the treatment of episodic cluster headache to reduce the frequency of migraine headaches and cluster headache attacks; it potently and selectively binds CGRP preventing its biological activity without blocking the CGRP receptor [15]. Phase 2 and 3 migraine prevention studies showed that galcanezumab reduced monthly migraine headache days and had a favorable short-term safety and tolerability compared with placebo [16-24].

A recent meta-analysis of randomized controlled trials of CGRP monoclonal antibodies for the prevention of episodic migraine supported the findings of safety and tolerability of CGRP monoclonal antibodies [25]. The meta-analysis included ten phase 2 and phase 3 clinical trials; four of those trials were galcanezumab studies. The studies included had a duration of up to 6 months, which prompted the authors to question the long-term safety and tolerability of CGRP monoclonal antibodies.

Our objective here is to report integrated safety data compared with placebo for up to 6 months in a large cohort of patients with migraine and to confirm the safety and tolerability profile in patients receiving galcanezumab up to 1 year.

\section{Methods}

\section{Study design}

Data from three double-blind phase 3 studies (EVOLVE1 [19], EVOLVE-2 [20], and REGAIN [21]), were integrated and included once-monthly, subcutaneous doses of galcanezumab (120 mg [with an initial loading dose of $240 \mathrm{mg}$ ] and $240 \mathrm{mg}$ ) compared with placebo (Table 1). Integration of data was justified since all studies were placebo controlled, all used the same randomization ratios of placebo: galcanezumab $120 \mathrm{mg}$ : galcanezumab $240 \mathrm{mg}$ dose-groups (2:1:1), and had comparable study designs. Furthermore, the safety results among the individual studies were consistent.

The data for all-galcanezumab exposures from patients treated with $120 \mathrm{mg}$ or $240 \mathrm{mg}$ of galcanezumab in phase 2 and 3 migraine prevention studies which included the 9-month open-label extension phase for REGAIN, the 1year safety study CGAJ [22], and the 3-month doubleblind study CGAB [18] are also presented (Table 1). The all-galcanezumab exposure group is used to compare longer exposure time to galcanezumab to the integrated double-blind studies that exposed patients to galcanezumab for a shorter period. Trial registration information is presented in Table 1 .

\section{Participants}

The inclusion and exclusion criteria for all studies have been published previously [17-21]. Key exclusion criteria included presence of a medical condition that would preclude study participation including pregnancy, suicidal ideation within the past month, history of substance abuse or dependence in the past year, lifetime history of stroke (REGAIN and EVOLVE-2) or within 6 months of screening (CGAB, EVOLVE-1 and CGAJ), and patients at-risk for acute (within 6 months of screening) or serious $\mathrm{CV}$ events as judged by the investigator. Patients with other comorbid CV conditions were included.

Patients were categorized into the CV disease risk subgroup "yes" if the patient reported one or more preexisting or medical history events included in the narrow search terms of the following standard Medical Dictionary for Regulatory Activities (MedDRA ${ }^{\circ}$ v.19.1) queries (SMQs): Ischemic heart disease, Hypertension, Cardiac failure, Cardiomyopathy, Ischemic central nervous system vascular conditions, Dyslipidemia, and Hyperglycemia/ new onset diabetes mellitus; patients who did not report any of these conditions prior to study randomization were categorized as "no" for CV disease risk group.

\section{Procedures}

Each of the studies included objectives to compare the safety and tolerability of galcanezumab with placebo in patients with episodic or chronic migraine using the following measures: treatment-emergent adverse events (TEAEs), serious adverse events (SAEs), discontinuation due to adverse events (DCAE), laboratory measures, temperature, blood pressure (BP), pulse, weight, suicidal ideation/behavior, and electrocardiogram (ECG).

\section{Outcomes}

In these studies, an adverse drug reaction (ADR) was identified by the study sponsor as a clinical event reasonably associated with galcanezumab treatment. Using 


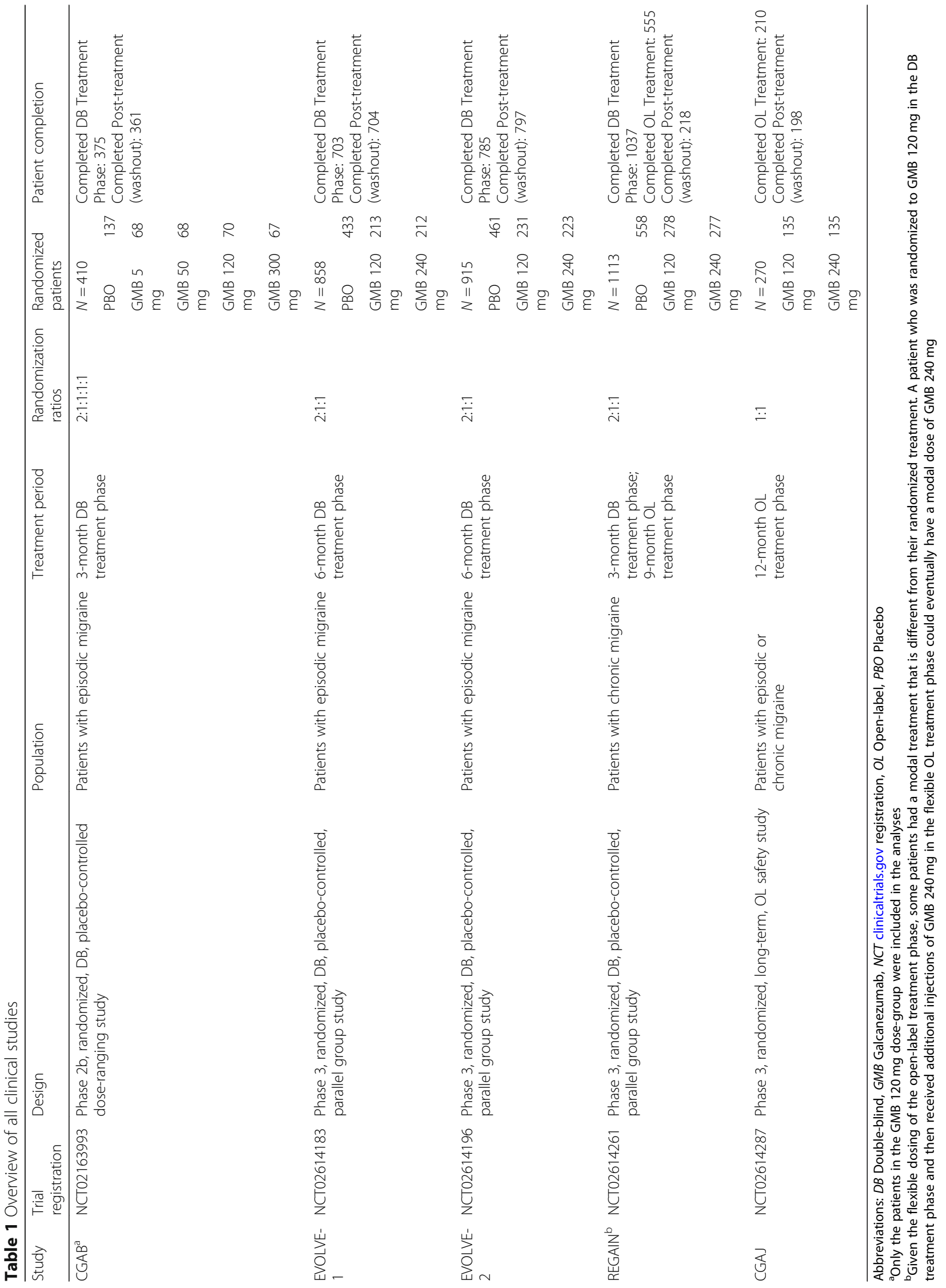


medical judgement, all AEs and numerical safety data were evaluated for a possible causal relationship to galcanezumab exposure. Factors used to determine the list of ADRs included the following: a statistical assessment of the effect via odds ratios and significance, any dose relationship, biologic plausibility, clinical relevance of any individual case (e.g., any available de-challenge/rechallenge information), the severity of the event, the consistency of findings across studies, similar events, and similar compounds.

The assessment of hypersensitivity events was conducted using the Hypersensitivity SMQ. Medical review of each case identified by the SMQ was conducted to determine whether the identified terms represented events that were likely hypersensitivity in nature.

Changes from baseline for continuous laboratory analyses were assessed and included a complete blood cell panel, clinical chemistry, and urinalysis.

Changes in hepatic function were assessed by treatmentemergent (TE) changes in hepatic laboratory measures and defined as any change from a baseline normal (i.e., $\leq 1$ times the upper limit of normal [ULN]) to a post-baseline abnormal high. Those tests included alanine aminotransferase or aspartate aminotransferase (either $\geq 3,5$, or 10 times the ULN); alkaline phosphatase ( $\geq 2$ times ULN), or total bilirubin ( $\geq 2$ times the ULN).

At every office visit, temperature was collected, BP and pulse were measured in triplicate (values were averaged for each visit and recorded as such) in the sitting position prior to blood draws and administration of study drug, and suicidal ideation and behavior was assessed using the Columbia-Suicide Severity Rating Scale (C-SSRS). The CSSRS scale captures the occurrence, severity, and frequency of suicide-related thoughts and behaviors during the assessment period [26]. A single, 12-lead digital ECG was collected at baseline and endpoint in the double-blind studies. Weight was collected at baseline and endpoint.

\section{Statistical analysis}

Time-at-risk-adjusted incidence rates per 100 patientyears, as well as unadjusted proportions, were calculated for TEAEs, SAEs, and DCAEs except for AEs related to injection sites, as these events mainly occur on the day of injection, a time-at-risk adjustment is not appropriate due to non-constant hazard over time. Treatment comparisons for proportions for categorical data (TEAE, SAE, DCAE, and TE abnormal hepatic laboratory measures, TE ECG findings, vital signs, and C-SSRS) were analyzed using the Cochran-Mantel-Haenszel test stratified by study. Treatment comparisons for time-atrisk-adjusted incidence rates were from likelihood ratio test from a Poisson regression with study and treatment as independent variables and time at risk as offset term. Treatment comparisons in mean change of continuous measures (laboratory measures, quantitative ECG measures, and vital signs) were analyzed using analysis of covariance models containing terms of treatment, study, and baseline measurement (Type III sums of squares).

All analyses were conducted for the safety population (all patients who were randomized and treated with at least one dose of study drug), and results were summarized by patient's modal treatment group during study period of interest. Statistical comparisons ( $p$-values) were conducted as exploratory without control for multiple testing. The statistical package used was SAS Enterprise Guide 7.0 (SAS Institute, Cary, NC).

\section{Results}

Patients demographics and disposition Integrated double-blind phase 3 studies

The safety population $(N=2886)$ was an average age of 41.0 years, mostly female $(84.5 \%)$, white $(76.7 \%)$, and from North America (67.4\%). Baseline characteristics by treatment group are summarized in Table 2. Based on reported medical history obtained prior to study initiation, 17.2 to $18.5 \%$ of all patients were identified in the $\mathrm{CV}$ disease risk-subgroup designation "yes". The most common conditions in the CV disease risk group were related to hypertension (placebo $=$ $10.3 \%$, galcanezumab $=7.9 \%$ ), dyslipidemia (placebo $=9.0 \%$, galcanezumab $=10.2 \%$ ), and hyperglycemia/new onset diabetes mellitus (placebo $=3.2 \%$, galcanezumab $=2.9 \%$ ). Patients in these three studies reflected the general population of patients with migraine with regard to demographics, disease characteristics, and comorbid medical conditions [27]. For the REGAIN study, the protocol allowed for up to one third of patients to continue on a stable dose of either topiramate or propranolol for migraine prevention, but only $14.6 \%$ of patients randomized were receiving a concomitant medication for migraine prevention; most of those patients received topiramate (10.3\%) compared to propranolol (4.3\%). Additionally, among patients with chronic migraine in the REGAIN study, $64 \%$ met the criteria for medication overuse and medication overuse headache was reported at baseline at similar rates among the treatment groups (placebo $=63.4 \%$, galcanezumab $120 \mathrm{mg}=64.3 \%$, and galcanezumab $240 \mathrm{mg}=$ 64.1\%).

Among all three studies, $89.1 \%$ of patients treated with galcanezumab completed double-blind treatment compared with $85.9 \%$ of placebo-treated patients. The most frequently reported reasons for discontinuation were patient decision, lost to follow-up, and AEs. No deaths were reported in any of the three studies. A total of 1435 patients were exposed to galcanezumab during the placebo-controlled phase of the three studies, which represented 536.3 patient-years of exposure (galcanezumab $120 \mathrm{mg}=267.7$ patient-years and galcanezumab 240 $\mathrm{mg}=268.7$ patient-years). 
Table 2 Baseline patient demographics and disease characteristics of the integrated double-blind studies

\begin{tabular}{|c|c|c|c|}
\hline & & Galcanezur & \\
\hline & $\begin{array}{l}\text { Placebo } \\
N=1451 \\
\mathrm{n}(\%)\end{array}$ & $\begin{array}{l}120 \mathrm{mg} \\
N=705 \\
\mathrm{n}(\%)\end{array}$ & $\begin{array}{l}240 \mathrm{mg} \\
N=730 \\
\mathrm{n}(\%)\end{array}$ \\
\hline Age & & & \\
\hline$<30$ years & $269(18.5)$ & $139(19.7)$ & $158(21.6)$ \\
\hline$\geq 30$ and $<40$ years & $342(23.6)$ & $182(25.8)$ & $194(26.6)$ \\
\hline$\geq 40$ and $<50$ years & $435(30.0)$ & 199 (28.2) & $192(26.3)$ \\
\hline$\geq 50$ years & $405(27.9)$ & $185(26.2)$ & $186(25.5)$ \\
\hline Sex & & & \\
\hline Male & $214(14.8)$ & $106(15.0)$ & $121(16.6)$ \\
\hline Female & $1237(85.3)$ & $599(85.0)$ & $609(83.4)$ \\
\hline Race & & & \\
\hline American Indian or Alaska Native & $24(1.7)$ & $10(1.4)$ & $16(2.2)$ \\
\hline Asian & $89(6.1)$ & $48(6.8)$ & $42(5.8)$ \\
\hline Black or African American & $117(8.1)$ & $53(7.5)$ & $59(8.1)$ \\
\hline Native Hawaiian, Other Pacific Islander & $2(0.1)$ & $0(0.0)$ & $4(0.6)$ \\
\hline White & $1112(76.6)$ & $545(77.3)$ & $555(76.1)$ \\
\hline Multiple & $107(7.4)$ & $49(7.0)$ & $53(7.3)$ \\
\hline Ethnicity & & & \\
\hline Hispanic or Latino & $298(20.5)$ & $149(21.1)$ & $170(23.3)$ \\
\hline Not Hispanic or Latino & $1077(74.2)$ & $522(74.0)$ & $530(72.6)$ \\
\hline Region & & & \\
\hline North America & $977(67.3)$ & $472(67.0)$ & $496(68.0)$ \\
\hline Europe & $262(18.1)$ & $126(17.9)$ & $131(18.0)$ \\
\hline Other & $212(14.6)$ & $107(15.2)$ & $103(14.1)$ \\
\hline Comorbid conditions occurring in $>10 \%$ & & & \\
\hline Seasonal allergy & $307(21.2)$ & $158(22.4)$ & $122(16.7) \mathrm{a}$ \\
\hline Drug hypersensitivity & $247(17.0)$ & $123(17.5)$ & $128(17.5)$ \\
\hline Insomnia & $165(11.4)$ & 89 (12.6) & $78(10.7)$ \\
\hline Anxiety & $166(11.4)$ & $82(11.6)$ & $81(11.1)$ \\
\hline Depression & $181(12.5)$ & $84(11.9)$ & $79(10.8)$ \\
\hline Back pain & $151(10.4)$ & $62(8.8)$ & $75(10.3)$ \\
\hline Cardiovascular disease risk group ${ }^{b}$ & & & \\
\hline Yes & $269(18.5)$ & $123(17.5)$ & $124(17.0)$ \\
\hline No & $1182(81.5)$ & $582(82.6)$ & $606(83.0)$ \\
\hline
\end{tabular}

Abbreviations: MedDRA Medical Dictionary for Regulatory Activities, $N$ Number of patients in the analysis population with non-missing demographic measures, $n$ Number of patients within each specific category

andicates a statistically significant difference $(P<0.05)$ compared with placebo

${ }^{\mathrm{b}}$ The following were standardized MedDRA ${ }^{\oplus}$ (certified terminology, and the international medical terminology developed under the auspices of the International Council for Harmonisation of Technical Requirements for Pharmaceuticals for Human Use) queries used to identify patients in the "yes" subgroup if patients affirmed one or more of the following as pre-existing or in their medical history: Ischaemic heart disease (including myocardial infarction, and other ischaemic heart disease), Hypertension, Cardiac failure, Cardiomyopathy, Ischaemic central nervous system vascular conditions, Dyslipidaemia and Hyperglycaemia/new onset diabetes mellitus

\section{All-galcanezumab exposure}

The demographics of this population were similar when compared to the integrated double-blind studies population. Across the five studies, a total of 2276 patients were exposed to galcanezumab $120 \mathrm{mg}$ or galcanezumab $240 \mathrm{mg}$, representing 1416.5 patient-years of exposure. A total of 526 patients were exposed to galcanezumab for a year. Table 1 presents patient disposition for all studies. 


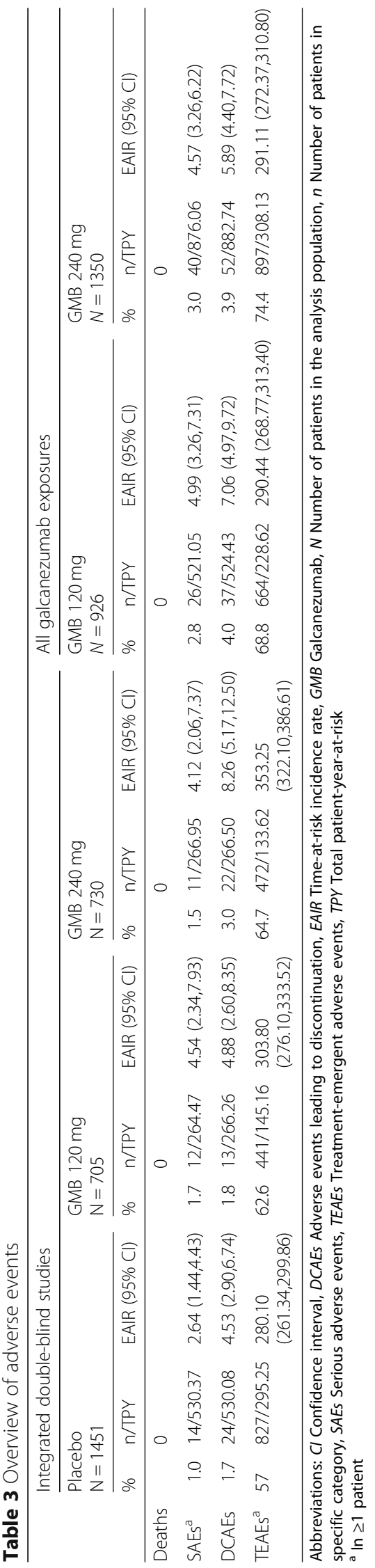




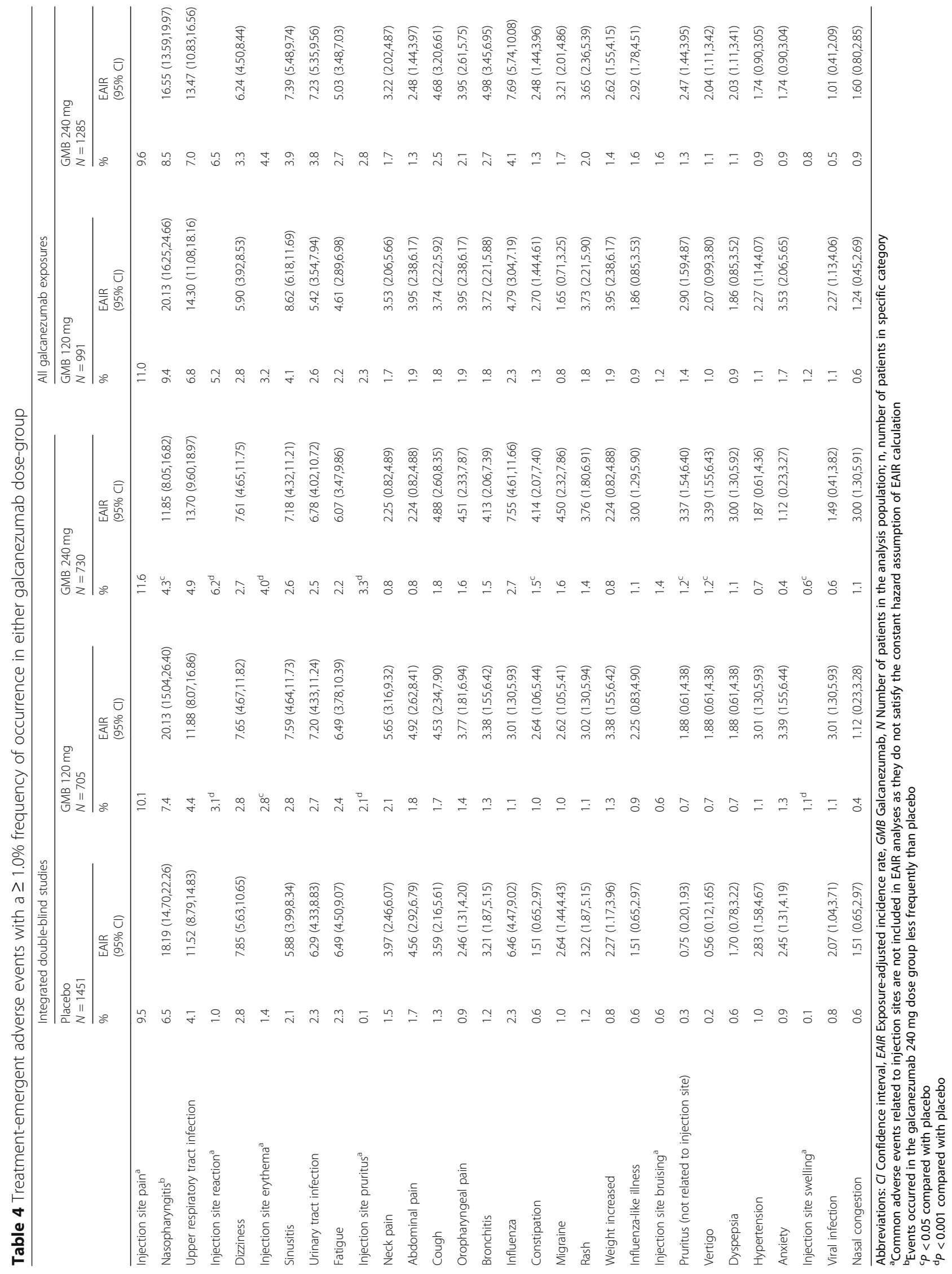




\section{Adverse events}

An overview of AEs by treatment group is shown in Table 3. The percentages and exposure adjusted incidence rates (EAIR) were higher for the galcanezumabtreated patients in the integrated double-blind studies compared to placebo. However, the EAIR did not increase with longer duration as shown in the allgalcanezumab exposure group. TEAEs that occurred in at least $1.0 \%$ of patients in either galcanezumab dosegroup and more frequently than in the placebo dosegroup during double-blind treatment are presented in Table 4. Injection site pain, injection site reactions excluding injection site pain, constipation, pruritus (not associated with injection site), and vertigo were considered ADRs associated with galcanezumab treatment.

\section{Injection site related adverse events}

Injection site pain was the most frequently reported of these events. The incidence was similar among treatment groups in the integrated double-blind studies and the allgalcanezumab exposure group (Table 4). Longer exposure to galcanezumab did not increase the frequency of injection site pain reported by galcanezumab-treated patients. Among patients in the integrated double-blind studies who reported injection site pain, regardless of the treatment group, most reported that the events occurred within $60 \mathrm{~min}$ of the injection $(84.9 \%)$, were mild to moderate in severity, occurred on the day of injection, and resolved in less than 3 days (galcanezumab $120 \mathrm{mg}=2.8$ days, galcanezumab $240 \mathrm{mg}=2.7$ days, and placebo $=2.0$ days). Galcanezumab-treated patients in the integrated double-blind studies who reported AEs related to injection sites other than injection site pain (galcanezumab $120 \mathrm{mg}=9.9 \%, P<0.001$; galcanezumab 240 $\mathrm{mg}=14.5 \%, P<0.001)$ did so at a higher rate than those treated with placebo (4.1\%).

No SAEs related to injection sites were reported. Seven patients discontinued galcanezumab treatment due to injection site-related AEs (Table 9).

\section{Treatment-emergent adverse events}

Constipation, pruritus (not associated with injection site), and vertigo were reported at a higher frequency in the galcanezumab treated patients compared with placebo (Table 4). The galcanezumab $240 \mathrm{mg}$ dose-group

Table 5 Common treatment-emergent adverse events by concurrent prophylaxis use in patients with chronic migraine

\begin{tabular}{|c|c|c|c|c|c|c|c|}
\hline & \multicolumn{3}{|c|}{ Concurrent prophylaxis use } & \multicolumn{3}{|c|}{ No concurrent prophylaxis use } & \multirow{3}{*}{$\begin{array}{l}\text { Interaction } \\
p \text {-value }\end{array}$} \\
\hline & $\begin{array}{l}\text { Placebo } \\
(N=82)\end{array}$ & $\begin{array}{l}\text { GMB } 120 \mathrm{mg} \\
(N=37)\end{array}$ & $\begin{array}{l}\text { GMB } 240 \mathrm{mg} \\
(N=43)\end{array}$ & $\begin{array}{l}\text { Placebo } \\
(N=476)\end{array}$ & $\begin{array}{l}\text { GMB } 120 \mathrm{mg} \\
(N=236)\end{array}$ & $\begin{array}{l}\text { GMB 240 mg } \\
(N=239)\end{array}$ & \\
\hline & n (\%) & n (\%) & n (\%) & n (\%) & n (\%) & n (\%) & \\
\hline Patients with $\geq 1$ TEAE & $42(51.22)$ & $21(56.76)$ & $22(51.16)$ & 237 (49.79) & $138(58.47)$ & $138(57.74)$ & 0.751 \\
\hline \multicolumn{8}{|l|}{ Common TEAE } \\
\hline Injection site pain & $2(2.44)$ & $4(10.81)$ & $1(2.33)$ & $22(4.62)$ & $13(5.51)$ & $19(7.95)$ & 0.162 \\
\hline Nasopharyngitis & $4(4.88)$ & $3(8.11)$ & $1(2.33)$ & $22(4.62)$ & $14(5.93)$ & $8(3.35)$ & 0.875 \\
\hline Injection site reaction & $1(1.22)$ & $0(0.00)$ & $1(2.33)$ & $9(1.89)$ & $8(3.39)$ & $14(5.86)$ & 0.839 \\
\hline Upper respiratory tract infection & $2(2.44)$ & $1(2.70)$ & $1(2.33)$ & $11(2.31)$ & $8(3.39)$ & $8(3.35)$ & 0.970 \\
\hline Back pain & $1(1.22)$ & $1(2.70)$ & $0(0.00)$ & $13(2.73)$ & $8(3.39)$ & $2(0.84)$ & 0.887 \\
\hline Fatigue & $1(1.22)$ & $1(2.70)$ & $0(0.00)$ & $9(1.89)$ & $5(2.12)$ & $6(2.51)$ & 0.689 \\
\hline Injection site erythema & $1(1.22)$ & $1(2.70)$ & $2(4.65)$ & $4(0.84)$ & $3(1.27)$ & $11(4.60)$ & 0.777 \\
\hline Abdominal pain & $2(2.44)$ & $2(5.41)$ & $0(0.00)$ & $7(1.47)$ & $4(1.69)$ & $4(1.67)$ & 0.629 \\
\hline Diarrhea & $2(2.44)$ & $1(2.70)$ & $1(2.33)$ & $7(1.47)$ & $2(0.85)$ & $5(2.09)$ & 0.776 \\
\hline Sinusitis & $1(1.22)$ & $0(0.00)$ & $2(4.65)$ & $4(0.84)$ & $4(1.69)$ & $6(2.51)$ & 0.800 \\
\hline Urinary tract infection & $2(2.44)$ & $0(0.00)$ & $2(4.65)$ & $5(1.05)$ & $6(2.54)$ & $2(0.84)$ & 0.249 \\
\hline Neck pain & $1(1.22)$ & $1(2.70)$ & $0(0.00)$ & $7(1.47)$ & $6(2.54)$ & $0(0.00)$ & 0.773 \\
\hline Migraine & $1(1.22)$ & $0(0.00)$ & $1(2.33)$ & $4(0.84)$ & $5(2.12)$ & $3(1.26)$ & 0.718 \\
\hline Influenza like illness & $2(2.44)$ & $1(2.70)$ & $0(0.00)$ & $1(0.21)$ & $4(1.69)$ & $4(1.67)$ & 0.274 \\
\hline Arthralgia & $0(0.00)$ & $0(0.00)$ & $2(4.65)$ & $5(1.05)$ & $1(0.42)$ & $3(1.26)$ & 0.471 \\
\hline Oropharyngeal pain & $0(0.00)$ & $0(0.00)$ & $1(2.33)$ & $3(0.63)$ & $2(0.85)$ & $4(1.67)$ & 0.898 \\
\hline Injection site pruritus & $0(0.00)$ & $0(0.00)$ & $0(0.00)$ & $1(0.21)$ & $0(0.00)$ & $7(2.93)$ & 0.473 \\
\hline Pyrexia & $0(0.00)$ & $1(2.70)$ & $0(0.00)$ & $2(0.42)$ & $4(1.69)$ & $1(0.42)$ & 0.932 \\
\hline
\end{tabular}

Abbreviations: GMB Galcanezumab, $N$ Number of subjects in safety population, $n$ Number of subjects within each specific category, TEAE Treatment-emergent adverse events

${ }^{a} P$-values: TEAE indicator $(\mathrm{Y} / \mathrm{N})=$ treatment, baseline medication overuse, concurrent prophylaxis use, and treatment by subgroup 
was statistically different compared to placebo for these TEAEs $(P<0.05)$. Most of the constipation and vertigo TEAEs were mild or moderate in severity, while the pruritus TEAEs were mild in severity. No patient discontinued due to these TEAEs. The EAIR of these TEAEs in the all-galcanezumab exposure $120 \mathrm{mg}$ and $240 \mathrm{mg}$ dose-group did not increase with longer treatment compared to integrated double-blind studies. In the patients with chronic migraine, there were no statistically significant differences in common TEAEs $(\geq 1.5 \%$ for galcanezumab treatment groups and greater than placebo) reported by patients with or without concurrent prophylaxis use and patients with or without medication overuse (Table 5 and Table 6).

\section{Hypersensitivity}

As shown in Table 7, there was a higher frequency of patients in the galcanezumab $120 \mathrm{mg}$ dose-group and galcanezumab $240 \mathrm{mg}$ dose-group reporting a hypersensitivity-related $\mathrm{AE}$ compared with placebo. No reports of anaphylaxis occurred. In the galcanezumab- treated patients, the severity of these events were $4.8 \%$ mild, $1.1 \%$ moderate, and $0.2 \%$ severe.

Urticaria was a hypersensitivity event that occurred in less than $0.3 \%$ of all-galcanezumab- and placebo-treated patients. Two patients reported an SAE of nonimmediate urticaria (occurred days after the last injection) during the open-label treatment period of the REGAIN study; neither patient reported other associated symptoms. Owing to the biological plausibility of the association between galcanezumab and these two SAEs, urticaria has been designated as an ADR associated with galcanezumab treatment. Neither of these two patients were positive for TE anti-drug antibodies.

\section{Serious adverse events}

Fewer than $2.0 \%$ of patients in either galcanezumab dose-group reported SAEs (Table 8); the percentage among placebo-treated patients was $1.0 \%$. A review of all SAEs did not reveal any patterns or notable differences between galcanezumab- and placebo-treated patients, nor between galcanezumab dose-groups (Table 8).

Table 6 Common treatment-emergent adverse events by medication overuse in patients with chronic migraine

\begin{tabular}{|c|c|c|c|c|c|c|c|}
\hline & \multicolumn{3}{|c|}{ Medication overuse } & \multicolumn{3}{|c|}{ No medication overuse } & \multirow{3}{*}{$\begin{array}{l}\text { Interaction } \\
p \text {-value }\end{array}$} \\
\hline & $\begin{array}{l}\text { Placebo } \\
(N=353)\end{array}$ & $\begin{array}{l}\text { GMB } 120 \mathrm{mg} \\
(N=178)\end{array}$ & $\begin{array}{l}\text { GMB } 240 \mathrm{mg} \\
(N=177)\end{array}$ & $\begin{array}{l}\text { Placebo } \\
(N=204)\end{array}$ & $\begin{array}{l}\text { GMB } 120 \mathrm{mg} \\
(N=94)\end{array}$ & $\begin{array}{l}\text { GMB } 240 \mathrm{mg} \\
(N=104)\end{array}$ & \\
\hline & n (\%) & n (\%) & n (\%) & n (\%) & n (\%) & n (\%) & \\
\hline Patients with $\geq 1 \mathrm{TEAE}$ & $169(47.88)$ & $99(55.62)$ & $99(55.93)$ & $110(53.92)$ & $59(62.77)$ & $60(57.69)$ & 0.800 \\
\hline \multicolumn{8}{|l|}{ Common TEAE } \\
\hline Injection site pain & $15(4.25)$ & $9(5.06)$ & $11(6.21)$ & $9(4.41)$ & $8(8.51)$ & $9(8.65)$ & 0.734 \\
\hline Nasopharyngitis & $13(3.68)$ & $11(6.18)$ & $6(3.39)$ & $13(6.37)$ & $6(6.38)$ & $3(2.88)$ & 0.597 \\
\hline Injection site reaction & $10(2.83)$ & $5(2.81)$ & $12(6.78)$ & $0(0.00)$ & $3(3.19)$ & $3(2.88)$ & 0.209 \\
\hline Upper respiratory tract infection & $10(2.83)$ & $6(3.37)$ & $6(3.39)$ & $3(1.47)$ & $3(3.19)$ & $3(2.88)$ & 0.795 \\
\hline Back pain & $9(2.55)$ & $6(3.37)$ & $2(1.13)$ & $5(2.45)$ & $3(3.19)$ & $0(0.00)$ & 0.789 \\
\hline Fatigue & $5(1.42)$ & $3(1.69)$ & $4(2.26)$ & $5(2.45)$ & $3(3.19)$ & $2(1.92)$ & 0.771 \\
\hline Injection site erythema & $3(0.85)$ & $1(0.56)$ & $6(3.39)$ & $2(0.98)$ & $3(3.19)$ & $7(6.73)$ & 0.596 \\
\hline Abdominal pain & $7(1.98)$ & $3(1.69)$ & $1(0.56)$ & $2(0.98)$ & $3(3.19)$ & $2(1.92)$ & 0.340 \\
\hline Diarrhea & $7(1.98)$ & $2(1.12)$ & $3(1.69)$ & $2(0.98)$ & $1(1.06)$ & $3(2.88)$ & 0.566 \\
\hline Sinusitis & $2(0.57)$ & $2(1.12)$ & $7(3.95)$ & $3(1.47)$ & $2(2.13)$ & $1(0.96)$ & 0.216 \\
\hline Urinary tract infection & $3(0.85)$ & $4(2.25)$ & $2(1.13)$ & $4(1.96)$ & $2(2.13)$ & $1(0.96)$ & 0.727 \\
\hline Neck pain & $5(1.42)$ & $4(2.25)$ & $0(0.00)$ & $3(1.47)$ & $3(3.19)$ & $0(0.00)$ & 0.946 \\
\hline Migraine & $4(1.13)$ & $3(1.69)$ & $3(1.69)$ & $1(0.49)$ & $2(2.13)$ & $1(0.96)$ & 0.771 \\
\hline Influenza like illness & $2(0.57)$ & $3(1.69)$ & $2(1.13)$ & $1(0.49)$ & $2(2.13)$ & $2(1.92)$ & 0.929 \\
\hline Arthralgia & $4(1.13)$ & $0(0.00)$ & $2(1.13)$ & $1(0.49)$ & $1(1.06)$ & $3(2.88)$ & 0.351 \\
\hline Oropharyngeal pain & $2(0.57)$ & $1(0.56)$ & $3(1.69)$ & $1(0.49)$ & $1(1.06)$ & $2(1.92)$ & 0.922 \\
\hline Injection site pruritus & $0(0.00)$ & $0(0.00)$ & $4(2.26)$ & $1(0.49)$ & $0(0.00)$ & $3(2.88)$ & 0.729 \\
\hline Pyrexia & $1(0.28)$ & $2(1.12)$ & $0(0.00)$ & $1(0.49)$ & $3(3.19)$ & $1(0.96)$ & 0.856 \\
\hline
\end{tabular}

Abbreviations: GMB Galcanezumab, $N$ Number of subjects in safety population, $n$ Number of subjects within each specific category, TEAE Treatment-emergent adverse events

${ }^{a} P$-values: TEAE indicator $(\mathrm{Y} / \mathrm{N})=$ treatment, baseline medication overuse, concurrent prophylaxis use, and treatment by subgroup Note: 3 patients in the analysis population had missing medication overuse 
Table 7 Percentage of patients in integrated double-blind studies who experienced a hypersensitivity event ${ }^{a, b}$

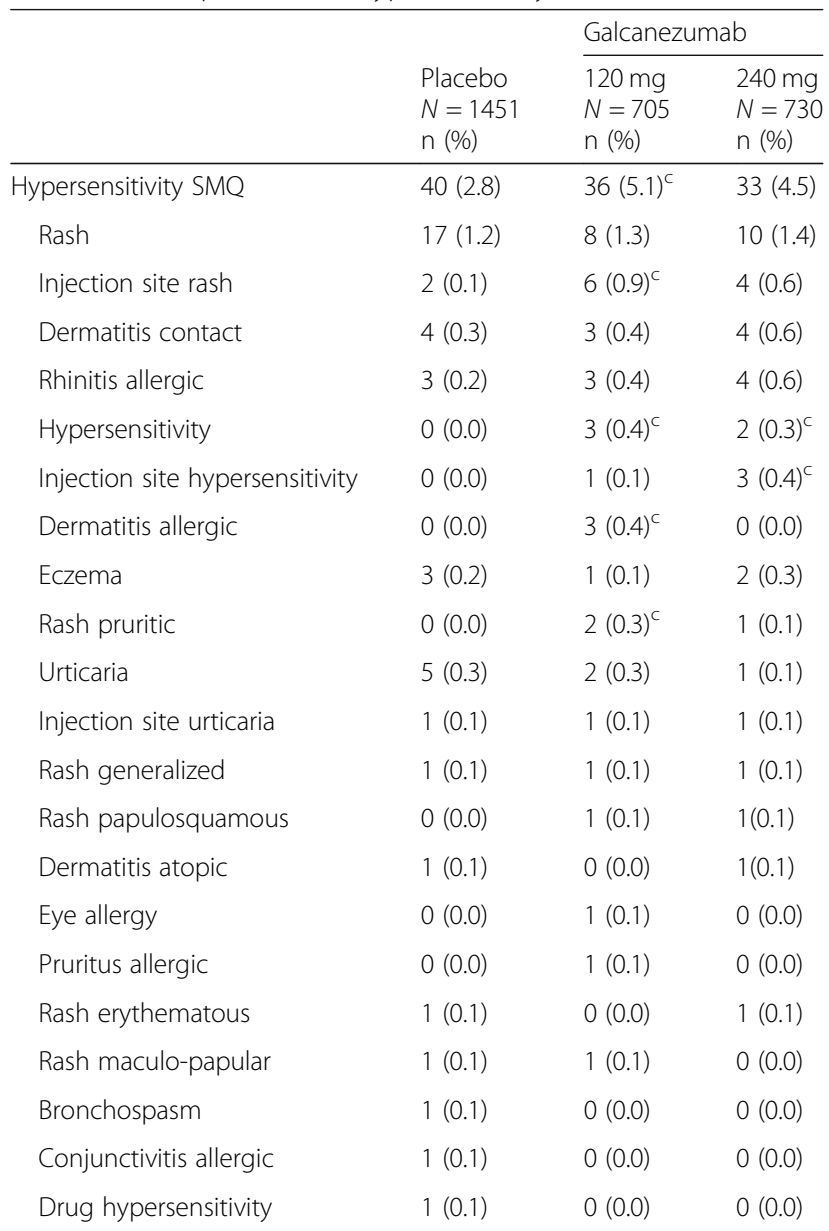

Abbreviations: MedDRA Medical Dictionary for Regulatory Activities, $N$ Number of patients in the analysis population, $n$ Number of patients within each specific category; SMQ, standardized MedDRA query

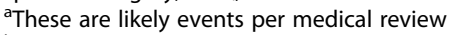

${ }^{\mathrm{b}}$ Categorized by narrow standardized MedDRA ${ }^{\oplus \mathrm{b}}$ (v.19.1) query search terms. MedDRA ${ }^{\oplus}$, the certified Medical Dictionary for Regulatory Activities

terminology, is the international medical terminology developed under the auspices of the International Council for Harmonisation of Technical

Requirements for Pharmaceuticals for Human Use

Indicates a statistically significant difference $(P<0.05)$ compared with placebo

Furthermore, the EAIRs for SAEs reported by at least one patient demonstrated no trend of an increase with longer treatment duration (Table 3).

There were no SAEs reported more than once with the exception of acute pancreatitis $(n=2)$, which was reported by one patient in each of the two galcanezumab dose-groups; cholelithiasis was reported by two placebotreated patients. Regarding the SAEs of pancreatitis, one was in a patient in the galcanezumab $240 \mathrm{mg}$ dosegroup. Five days after the first dose of galcanezumab the patient was admitted to the hospital with epigastric pain which had started prior to treatment randomization; lipase was elevated (14,663 units per litre [normal range is 73-393 units per litre]). Ultrasonography showed significant sludge in the gallbladder, and the computed tomography scan was consistent with pancreatitis of the pancreatic tail. The patient was discharged from the hospital, re-admitted twice in the following weeks, and finally underwent an endoscopic sphincterotomy and laparoscopic cholecystectomy, which showed numerous pigmented black gallbladder stones. A likely cause for pancreatitis in this patient was the presence of the gallbladder stones; additionally, this event was confounded by concomitant topiramate use. The patient discontinued from the study. In the opinion of the investigator, the pancreatitis was not related to study drug treatment. The other SAE of pancreatitis was reported by a patient in the galcanezumab $120 \mathrm{mg}$ dose-group. Four days after the second dose of galcanezumab, the patient presented with abdominal pain and was diagnosed with pancreatitis; lipase level was only slightly above the ULN (411 units per litre). The abdominal computed tomography report stated that the patient had ileus of the distal small bowel which could explain the abdominal symptoms, but was not consistent with pancreatitis. A similar incident occurred in this patient previously. The event resolved, and the patient completed both the treatment and post-treatment periods of the study. Again, in the opinion of the investigator, pancreatitis was not related to the treatment with galcanezumab.

\section{Cardiovascular related serious adverse events}

$\mathrm{CV}$-related SAEs were reported at a similar frequency by galcanezumab- and placebo-treated patients, and included myocardial infarction, pulmonary embolism, deep vein thrombosis, and transient ischemic attack (Table 8).

\section{Discontinuations due to adverse events}

Although the percentage of DCAEs was not more than $3.0 \%$ among all treatment groups, DCAEs were statistically different among galcanezumab $240 \mathrm{mg}$ treated patients compared to placebo (Table 9). AE leading to discontinuation in at least two galcanezumab-treated patients were as follows: worsening of migraine $(n=5)$, injection site reaction $(n=4)$, hepatic enzyme increased $(n=2)$, nasopharyngitis $(\mathrm{n}=2)$, and weight increase $(\mathrm{n}=2)$. The EAIRs for DCAEs demonstrated no trend of an increase with longer treatment duration (Table 3).

\section{Discontinuations due to cardiovascular related adverse events}

CV-related AEs leading to discontinuation in placebotreated patients were myocardial infarction, deep vein thrombosis, and hypertension (Table 9). The specific CVrelated $\mathrm{AE}$ leading to discontinuation in one galcanezumabtreated patient was transient ischemic attack. 
Table 8 Serious adverse events by system organ class that occurred in either galcanezumab dose-groups compared with placebo during double-blind treatment

\begin{tabular}{|c|c|c|c|}
\hline & & Galcanez & \\
\hline & $\begin{array}{l}\text { Placebo } \\
N=1451 \\
\mathrm{n}(\%)\end{array}$ & $\begin{array}{l}120 \mathrm{mg} \\
N=705 \\
\mathrm{n}(\%)\end{array}$ & $\begin{array}{l}240 \mathrm{mg} \\
N=730 \\
\mathrm{n}(\%)\end{array}$ \\
\hline Patients with at least one SAE & $14(1.0)$ & $12(1.7)$ & $11(1.5)$ \\
\hline Cardiac disorders & $1(0.1)$ & $0(0.0)$ & $1(0.1)$ \\
\hline Acute myocardial infarction & $0(0.0)$ & $0(0.0)$ & $1(0.1)$ \\
\hline Myocardial infarction & $1(0.7)$ & $0(0.0)$ & $0(0.0)$ \\
\hline Gastrointestinal disorders & $3(0.2)$ & $4(0.6)$ & $1(0.1)$ \\
\hline Pancreatitis acute & $0(0.0)$ & $1(0.1)$ & $1(0.1)$ \\
\hline Gastritis & $1(0.1)$ & $1(0.1)$ & $0(0.0)$ \\
\hline Rectal polyp & $0(0.0)$ & $1(0.1)$ & $0(0.0)$ \\
\hline Small intestinal obstruction & $0(0.0)$ & $1(0.1)$ & $0(0.0)$ \\
\hline Alcoholic pancreatitis & $1(0.1)$ & $0(0.0)$ & $0(0.0)$ \\
\hline Hemorrhoids & $1(0.1)$ & $0(0.0)$ & $0(0.0)$ \\
\hline General disorders and administration site conditions & $0(0.0)$ & $0(0.0)$ & $1(0.1)$ \\
\hline Pyrexia & $0(0.0)$ & $0(0.0)$ & $1(0.1)$ \\
\hline Hepatobiliary disorders & $3(0.2)$ & $0(0.0)$ & $1(0.1)$ \\
\hline Cholelithiasis & $2(0.1)$ & $0(0.0)$ & $1(0.1)$ \\
\hline Gallbladder polyp & $1(0.1)$ & $0(0.0)$ & $0(0.0)$ \\
\hline Infections and infestations & $0(0.0)$ & $1(0.1)$ & $1(0.1)$ \\
\hline Influenza & $0(0.0)$ & $0(0.0)$ & $1(0.1)$ \\
\hline Injury, poisoning and procedural complications & $1(0.1)$ & $2(0.3)$ & $1(0.1)$ \\
\hline Incarcerated incisional hernia & $0(0.0)$ & $1(0.1)$ & $0(0.0)$ \\
\hline Ligament rupture & $0(0.0)$ & $1(0.1)$ & $0(0.0)$ \\
\hline Meniscus injury & $0(0.0)$ & $0(0.0)$ & $1(0.1)$ \\
\hline Seroma & $0(0.0)$ & $1(0.1)$ & $0(0.0)$ \\
\hline Foot fracture & $1(0.1)$ & $0(0.0)$ & $0(0.0)$ \\
\hline Rib fracture & $1(0.1)$ & $0(0.0)$ & $0(0.0)$ \\
\hline Road traffic accident & $1(0.1)$ & $0(0.0)$ & $0(0.0)$ \\
\hline Metabolism and nutrition disorders & $0(0.0)$ & $0(0.0)$ & $1(0.1)$ \\
\hline Hypokalemia & $0(0.0)$ & $0(0.0)$ & $1(0.1)$ \\
\hline Musculoskeletal and connective tissue disorders & $1(0.1)$ & $1(0.1)$ & $0(0.0)$ \\
\hline Tendonitis & $0(0.0)$ & $1(0.1)$ & $0(0.0)$ \\
\hline Vertebral osteophyte & $1(0.1)$ & $0(0.0)$ & $0(0.0)$ \\
\hline Neoplasms benign, malignant and unspecified & $0(0.0)$ & $3(0.4)$ & $0(0.0)$ \\
\hline Adenocarcinoma of the cervix & $0(0.0)$ & $1(0.2)$ & $0(0.0)$ \\
\hline Colon cancer & $0(0.0)$ & $1(0.1)$ & $0(0.0)$ \\
\hline Tubular breast carcinoma & $0(0.0)$ & $1(0.1)$ & $0(0.0)$ \\
\hline Nervous system disorders & $1(0.1)$ & $0(0.0)$ & $2(0.3)$ \\
\hline Generalized tonic-clonic seizure & $0(0.0)$ & $0(0.0)$ & $1(0.1)$ \\
\hline Transient ischemic attack & $0(0.0)$ & $0(0.0)$ & $1(0.1)$ \\
\hline Migraine & $1(0.1)$ & $0(0.0)$ & $0(0.0)$ \\
\hline Psychiatric disorders & $1(0.1)$ & $0(0.0)$ & $1(0.1)$ \\
\hline Disorientation & $0(0.0)$ & $0(0.0)$ & $1(0.1)$ \\
\hline
\end{tabular}


Table 8 Serious adverse events by system organ class that occurred in either galcanezumab dose-groups compared with placebo during double-blind treatment (Continued)

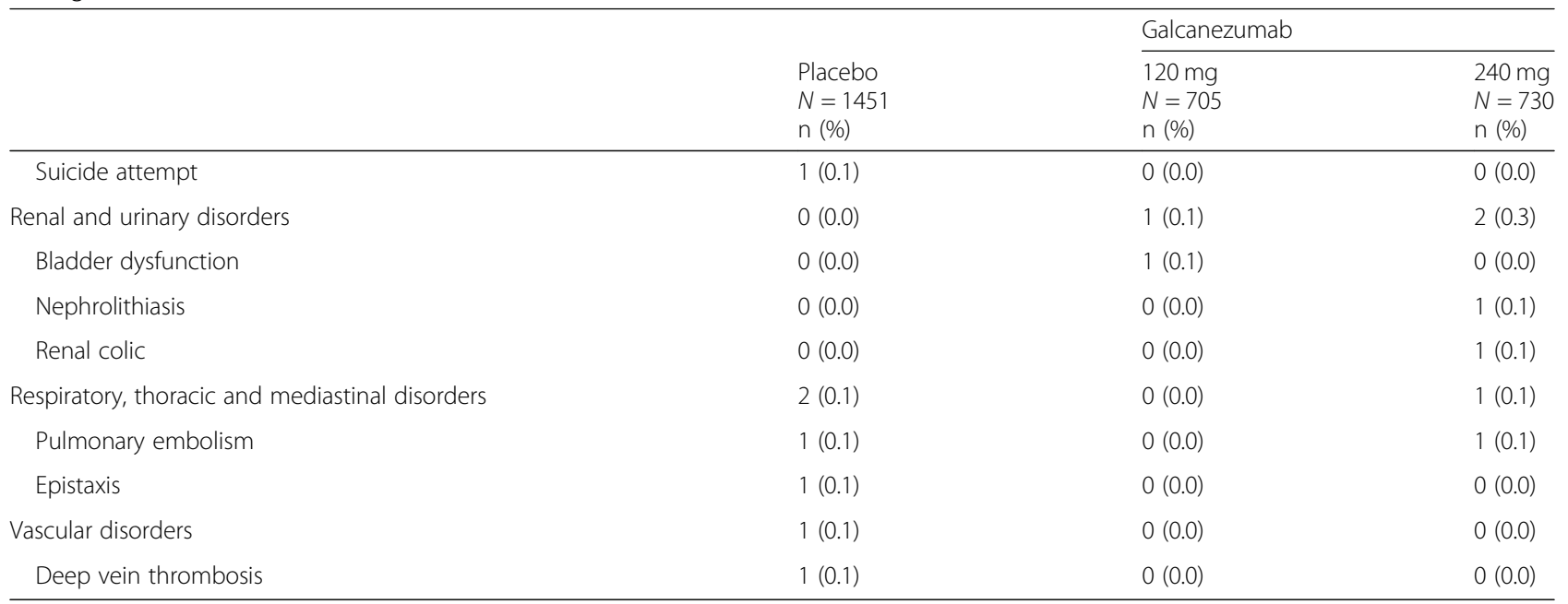

Abbreviations: $N$ Number of patients in the analysis population, $n$ Number of patients within each specific category, SAE Serious adverse event

\section{Laboratory assessments including hepatic laboratory measures}

There were no significant or clinically meaningful differences in mean change from baseline in the analyses of laboratory parameters for patients in galcanezumab-treated group compared with placebo. Galcanezumab treatment was not associated with any significant or clinically meaningful abnormalities of chemistry, hematology, or urinalysis laboratory analytes; mean changes in routine laboratory parameters were generally minimal. For laboratory values related to glucose and lipid metabolism, no clinically significant mean changes were observed.

There were no clinically relevant differences between patients treated with galcanezumab or placebo in the incidence of TE hepatic laboratory changes, the frequencies for any of these abnormalities were less than $1.0 \%$ (Table 10). Overall, for patients with TE hepatic laboratory changes, there were no patterns that would suggest an association with galcanezumab. No Hy's Law cases were observed in any patient during these studies.

\section{Vital signs, weight, and ECGs}

Mean changes in temperature were not statistically different among any treatment group in these studies.

During the double-blind treatment period, mean changes from baseline to endpoint in systolic and diastolic BP, and pulse were minimal $(\leq 1.0 \mathrm{mmHg}$ and $\leq 2$ $\mathrm{bpm}$, respectively). The frequency of TE or sustained increases in BP, and pulse at any time was similar in galcanezumab- and placebo-treated patients, with no statistically significant or clinically meaningful differences (Table 11). Exposure-adjusted analysis of TE high systolic BP showed that in the integrated double-blind studies the EAIR was 8.7 for the galcanezumab $120 \mathrm{mg}$ dose-group and 9.6 for the galcanezumab $240 \mathrm{mg}$ dose- group, which was similar to placebo $(8.1$, IRR = 1.1-1.2). The exposure-adjusted analysis of TE high systolic BP showed that in the all-galcanezumab exposure group the EAIRs decreased for both treatment groups, 5.3 for the galcanezumab $120 \mathrm{mg}$ and 8.7 for the galcanezumab 240 mg dose-group, suggesting that the TE increases in systolic BP did not increase with longer treatment duration. The analysis for TE high diastolic BP resulted in an EAIR of 21.4 for the galcanezumab120 mg dose-group and 19.3 for the galcanezumab $240 \mathrm{mg}$ dose-group which was similar to placebo $(17.6, \mathrm{IRR}=1.1-1.2)$. The analysis for TE high diastolic BP in the all-galcanezumab exposure group resulted in an EAIR of 16.5 for the galcanezumab $120 \mathrm{mg}$ dose-group and 16.9 for the galcanezumab $240 \mathrm{mg}$ dose-group, demonstrating that the TE increases in diastolic BP did not increase with longer treatment duration.

A similar proportion of galcanezumab- and placebotreated patients either gained or lost at least $7.0 \%$ of their baseline weight (gained $\geq 7.0 \%$ : galcanezumab 120 $\mathrm{mg}=6.3 \%$, galcanezumab $240 \mathrm{mg}=6.4 \%$, placebo $=5.2 \%$; lost $\geq 7.0 \%$ : galcanezumab $120 \mathrm{mg}=3.9 \%$, galcanezumab $240 \mathrm{mg}=3.4 \%$, placebo $=2.6 \%$ ), and there were no clinically important or statistically different changes in weight between any treatment-group in these studies.

For ECG analysis, there were no clinically meaningful differences observed between treatment groups. No patient met clinically significant increases in QTcF (> 500 msec).

\section{Suicidal ideation or behavior}

Overall, data from galcanezumab-treated patients in these phase 3 studies do not suggest a risk of suicidal ideation or behavior as assessed by the C-SSRS. The integrated double-blind studies reported suicidal ideation 
Table 9 Adverse events leading to discontinuation of treatment by system organ class that occurred in either galcanezumab dosegroups compared with placebo during double-blind treatment

\begin{tabular}{|c|c|c|c|}
\hline & & Galcanez & \\
\hline & $\begin{array}{l}\text { Placebo } \\
N=1451 \\
\mathrm{n}(\%)\end{array}$ & $\begin{array}{l}120 \mathrm{mg} \\
N=705 \\
\mathrm{n}(\%)\end{array}$ & $\begin{array}{l}240 \mathrm{mg} \\
N=730 \\
\mathrm{n}(\%)\end{array}$ \\
\hline Patients with DCAE & $24(1.7)$ & $13(1.8)$ & $22(3.0)^{a}$ \\
\hline Cardiac disorder & $1(0.1)$ & $0(0.0)$ & $0(0.0)$ \\
\hline Myocardial infarction & $1(0.1)$ & $0(0.0)$ & $0(0.0)$ \\
\hline Ear and labyrinth disorder & $1(0.1)$ & $0(0.0)$ & $0(0.0)$ \\
\hline Vertigo & $1(0.1)$ & $0(0.0)$ & $0(0.0)$ \\
\hline Gastrointestinal disorders & $1(0.1)$ & $1(0.1)$ & $2(0.3)$ \\
\hline Dyspepsia & $0(0.0)$ & $0(0.0)$ & $1(0.1)$ \\
\hline Gastritis & $0(0.0)$ & $1(0.1)$ & $0(0.0)$ \\
\hline Pancreatitis acute & $0(0.0)$ & $0(0.0)$ & $1(0.1)$ \\
\hline Abdominal pain & $1(0.1)$ & $0(0.0)$ & $0(0.0)$ \\
\hline General disorders and administration site conditions & $2(0.1)$ & $3(0.4)$ & $7(1.0)$ \\
\hline Injection site reaction & $0(0.0)$ & $1(0.1)$ & $3(0.4)^{\dagger}$ \\
\hline Chest discomfort & $0(0.0)$ & $0(0.0)$ & $1(0.1)$ \\
\hline Influenza-like illness & $0(0.0)$ & $0(0.0)$ & $1(0.1)$ \\
\hline Injection site erythema & $0(0.0)$ & $1(0.1)$ & $0(0.0)$ \\
\hline Injection site pain & $0(0.0)$ & $0(0.0)$ & $1(0.1)$ \\
\hline Injection site swelling & $0(0.0)$ & $0(0.0)$ & $1(0.1)$ \\
\hline Peripheral swelling & $0(0.0)$ & $1(0.1)$ & $0(0.0)$ \\
\hline Facial pain & $1(0.1)$ & $0(0.0)$ & $0(0.0)$ \\
\hline Fatigue & $1(0.1)$ & $0(0.0)$ & $0(0.0)$ \\
\hline Hepatobiliary disorders & $1(0.1)$ & $0(0.0)$ & $0(0.0)$ \\
\hline Cholelithiasis & $1(0.1)$ & $0(0.0)$ & $0(0.0)$ \\
\hline Immune system disorders & $0(0.0)$ & $0(0.0)$ & $1(0.1)$ \\
\hline Hypersensitivity & $0(0.0)$ & $0(0.0)$ & $1(0.1)$ \\
\hline Infections and infestations & $1(0.1)$ & $0(0.0)$ & $3(0.4)$ \\
\hline Nasopharyngitis & $0(0.0)$ & $0(0.0)$ & $2(0.3)^{\dagger}$ \\
\hline Infection & $0(0.0)$ & $0(0.0)$ & $1(0.1)$ \\
\hline Tinea capitis & $1(0.1)$ & $0(0.0)$ & $0(0.0)$ \\
\hline Investigations & $0(0.0)$ & $2(0.3)$ & $2(0.3)$ \\
\hline Hepatic enzyme increased & $0(0.0)$ & $0(0.0)$ & $2(0.3)^{\dagger}$ \\
\hline Weight increase & $0(0.0)$ & $2(0.3)^{+}$ & $0(0.0)$ \\
\hline Musculoskeletal and connective tissue disorders & $3(0.2)$ & $1(0.1)$ & $0(0.0)$ \\
\hline Myalgia & $0(0.0)$ & $1(0.1)$ & $0(0.0)$ \\
\hline Arthralgia & $1(0.1)$ & $0(0.0)$ & $0(0.0)$ \\
\hline Pain in extremity & $1(0.1)$ & $0(0.0)$ & $0(0.0)$ \\
\hline Vertebral osteophyte & $1(0.1)$ & $0(0.0)$ & $0(0.0)$ \\
\hline Neoplasms benign, malignant and unspecified & $0(0.0)$ & $2(0.3)$ & $0(0.0)$ \\
\hline Adenocarcinoma of the cervix ${ }^{b}$ & $0(0.0)$ & $1(0.2)$ & $0(0.0)$ \\
\hline Tubular breast carcinoma & $0(0.0)$ & $1(0.1)$ & $0(0.0)$ \\
\hline Nervous system disorders & $7(0.5)$ & $1(0.1)$ & $4(0.6)$ \\
\hline Migraine & $3(0.2)$ & $1(0.1)$ & $4(0.6)$ \\
\hline
\end{tabular}


Table 9 Adverse events leading to discontinuation of treatment by system organ class that occurred in either galcanezumab dosegroups compared with placebo during double-blind treatment (Continued)

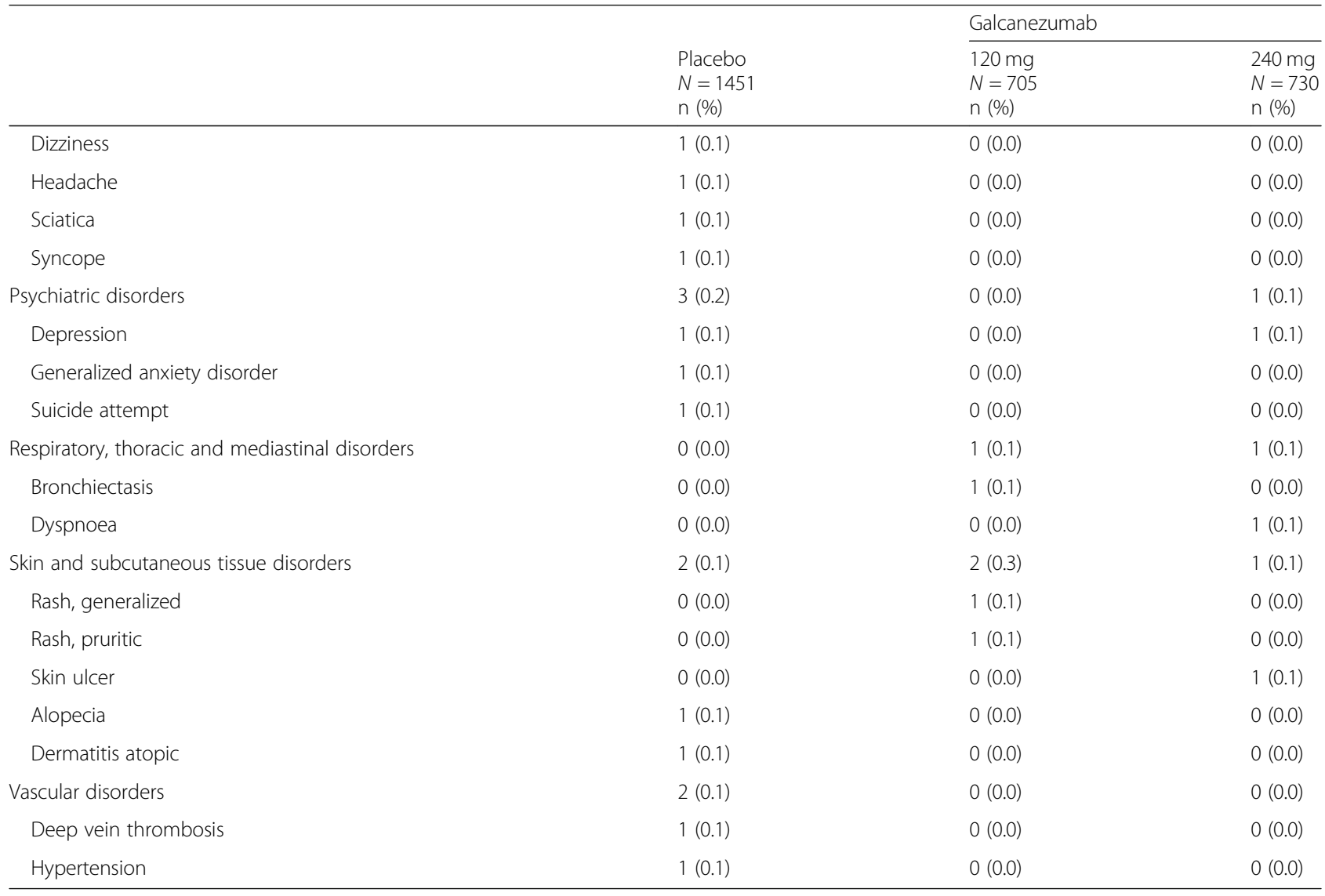

Abbreviations: DCAE Discontinued treatment due to an adverse event, $N$ Number of patients in the analysis population, $n$ Number of patients within each specific category

andicates a statistically significant difference $(P<0.05)$ compared with placebo

${ }^{\mathrm{b}}$ Denominator adjusted for female-specific event

in $13(0.9 \%)$ patients in the placebo group, $4(0.6 \%)$ patients in the galcanezumab $120 \mathrm{mg}$ dose-group, and 7 (1.0\%) patients in the galcanezumab $240 \mathrm{mg}$ dose-group. Suicidal behavior was reported in $1(0.1 \%)$ patient in the placebo group and in $1(0.1 \%)$ patient in the galcanezumab $240 \mathrm{mg}$ dose-group. The all-galcanezumab exposure group reported suicidal ideation in $11(1.1 \%)$ patients in the galcanezumab $120 \mathrm{mg}$ dose-group and $11(0.9 \%)$ patients in the galcanezumab $240 \mathrm{mg}$ dose-group. Suicidal behavior was reported in $1(0.1 \%)$ patient in each galcanezumab dose-group.

\section{Discussion}

In this integrated report of safety data from five clinical studies with up to a year of galcanezumab treatment, we have expanded available knowledge regarding the safety and tolerability of galcanezumab.

The most common AEs observed in our studies were those related to injection site, which are consistent with other marketed injectable CGRP monoclonal antibodies [28-36].
Although treatment with monoclonal antibodies can be associated with severe hypersensitivity adverse reactions, no anaphylaxis events were reported in these studies. However, two serious cases of non-immediate urticaria were reported in galcanezumab-treated patients during the open-label treatment phase of the REGAIN study. Hypersensitivity events generally occurred more frequently in patients treated with galcanezumab than with placebo, although most events were mild or moderate in severity and did not lead to discontinuation of galcanezumab treatment. A separate by-month analysis of hypersensitivity events (data on file) did not suggest a trend toward an increase in the frequency of hypersensitivity events with increased duration of treatment.

The events of constipation, vertigo, and pruritus were all reported in up to $1.0 \%$ of patients in the galcanezumab $120 \mathrm{mg}$ dose-group and up to $1.5 \%$ of patients in the $240 \mathrm{mg}$ dose-group. In the gastrointestinal system, CGRP affects visceral nociception, blood flow, inflammation, motility, colonic secretion, and is known to induce diarrhea in rodents [37], thus the ADR of constipation 
Table 10 Percentage of patients in integrated double-blind studies with treatment-emergent high hepatic laboratory measures at any time ${ }^{a}$

\begin{tabular}{|c|c|c|c|}
\hline \multirow[t]{2}{*}{ Analyte } & \multirow[t]{2}{*}{ Placebo } & \multicolumn{2}{|c|}{ Galcanezumab } \\
\hline & & $120 \mathrm{mg}$ & $240 \mathrm{mg}$ \\
\hline & $\begin{array}{l}N=1202 \\
\mathrm{n}(\%)\end{array}$ & $\begin{array}{l}N=591 \\
\mathrm{n}(\%)\end{array}$ & $\begin{array}{l}N=598 \\
\mathrm{n}(\%)\end{array}$ \\
\hline$A L T \geq 3 x \cup L N$ & $4(0.3)$ & $1(0.2)$ & $2(0.3)$ \\
\hline$A L T \geq 5 \times$ ULN & $0(0.0)$ & $1(0.2)$ & $1(0.2)$ \\
\hline \multirow[t]{2}{*}{$A L T \geq 10 x$ ULN } & $0(0.0)$ & $1(0.2)$ & $0(0.0)$ \\
\hline & $\begin{array}{l}N=1274 \\
n(\%)\end{array}$ & $\begin{array}{l}N=635 \\
\mathrm{n}(\%)\end{array}$ & $\begin{array}{l}N=636 \\
\mathrm{n}(\%)\end{array}$ \\
\hline $\mathrm{AST} \geq 3 \times \mathrm{ULN}$ & $1(0.1)$ & $1(0.2)$ & $1(0.2)$ \\
\hline AST $\geq 5 \times$ ULN & $0(0.0)$ & $0(0.0)$ & $0(0.0)$ \\
\hline \multirow[t]{2}{*}{ AST $\geq 10 \times$ ULN } & $0(0.0)$ & $0(0.0)$ & $0(0.0)$ \\
\hline & $\begin{array}{l}N=1295 \\
n(\%)\end{array}$ & $\begin{array}{l}N=648 \\
\mathrm{n}(\%)\end{array}$ & $\begin{array}{l}N=658 \\
\mathrm{n}(\%)\end{array}$ \\
\hline \multirow[t]{2}{*}{$A L P \geq 2 x \cup L N$} & $0(0.0)$ & $0(0.0)$ & $0(0.0)$ \\
\hline & $\begin{array}{l}N=1306 \\
\mathrm{n}(\%)\end{array}$ & $\begin{array}{l}N=647 \\
\mathrm{n}(\%)\end{array}$ & $\begin{array}{l}N=660 \\
\mathrm{n}(\%)\end{array}$ \\
\hline TBIL $\geq 2 x$ ULN & $0(0.0)$ & $0(0.0)$ & $0(0.0)$ \\
\hline
\end{tabular}

Abbreviations: ALT Alanine aminotransferase, ALP Alkaline phosphatase, AST Aspartate aminotransferase, $N$ Number of patients in the baseline category and at least one postbaseline measurement, $n$ Number of patients with at least one value in the postbaseline category, TBIL Total bilirubin, ULN Upper limit of normal

${ }^{a}$ Includes all patients with at least one post-baseline measurement and those with missing baseline values

seems biologically plausible. Erenumab, another antiCGRP medication, includes constipation as an ADR in product labeling [32]. Patients with migraine often report audiovestibular symptoms including vertigo, tinnitus, phonophobia, and hearing loss [38, 39]. Vertigo was categorized as an ADR since inhibition of CGRP may interfere with vestibular function [40, 41].

Differences between galcanezumab- and placebotreated patients were observed in the percentage of SAEs and DCAEs; however, the types of events reported were similar and there was not a distinct pattern specific to galcanezumab treatment. There were low numbers of CV-related SAEs or DCAEs with a similar number of events reported in the placebo and galcanezumab treatment groups. All the CV-related SAEs in galcanezumabtreated patients resolved with no additional CV TEAEs or sequelae reported. In the patient with the transient ischemic attack, 2 computerized tomogram scans and a brain MRI (including angiography of the extracranial and intracranial vessels and ergometry) performed following the event were judged normal and without signs of ischemia. Additionally, treatment with galcanezumab or placebo did not lead to an increase in systolic or diastolic BP with up to a year of treatment.

Hepatic safety of galcanezumab was reported previously [16, 42]; no Hy's Law observations were reported
Table 11 Percentage of patients in integrated double-blind studies reporting treatment-emergent changes to blood pressure and pulse

\begin{tabular}{llll}
\hline & \multicolumn{3}{l}{ Galcanezumab } \\
\cline { 3 - 4 } & Placebo & $120 \mathrm{mg}$ & $240 \mathrm{mg}$ \\
$\mathrm{n} / \mathrm{N}(\%)$ & $\mathrm{n} / \mathrm{N}(\%)$ & \\
\hline Systolic blood pressure & & \\
Low & $7 / 1399(0.5)$ & $3 / 698(0.4)$ & $8 / 706(1.1)$ \\
High & $40 / 1332(3.0)$ & $22 / 672(3.3)$ & $24 / 674(3.6)$ \\
PCS high & $1 / 1409(0.1)$ & $1 / 704(0.1)$ & $0 / 708(0.0)$ \\
Sustained & $7 / 1297(0.5)$ & $2 / 658(0.3)$ & $1 / 657(0.2)$ \\
Diastolic blood pressure & & \\
Low & $6 / 1404(0.4)$ & $2 / 704(0.3)$ & $8 / 709(1.1)$ \\
High & $83 / 1292(6.4)$ & $51 / 653(7.8)$ & $46 / 652(7.1)$ \\
PCS high & $8 / 1402(0.6)$ & $4 / 703(0.6)$ & $5 / 704(0.7)$ \\
Sustained & $15 / 1260(1.2)$ & $9 / 639(1.4)$ & $6 / 637(0.9)$ \\
Pulse & & & \\
Low & $5 / 1403(0.4)$ & $1 / 700(0.1)$ & $2 / 707(0.3)$ \\
High & $32 / 1398(2.3)$ & $13 / 702(1.9)$ & $15 / 705(2.1)$ \\
Sustained & $1 / 1361(0.1)$ & $0 / 688(0.0)$ & $1 / 687(0.2)$ \\
\hline
\end{tabular}

Abbreviations: $b p m$ Beats per minute, $N$ Number of patients in the analysis population, $n$ Number of patients within each specific category, PCS Possibly clinically significant

${ }^{\text {a } F o r ~ s y s t o l i c ~ b l o o d ~ p r e s s u r e: ~ t r e a t m e n t-e m e r g e n t ~ l o w ~} \leq 90 \mathrm{mmHg}$ with $\geq 20$ $\mathrm{mmHg}$ decrease; treatment-emergent high $\geq 140 \mathrm{mmHg}$ with $\geq 20 \mathrm{mmHg}$ increase; PCS high $\geq 180 \mathrm{mmHg}$ with $\geq 20 \mathrm{mmHg}$ increase; sustained elevation $\geq 140 \mathrm{mmHg}$ with $\geq 20 \mathrm{mmHg}$ increase for 2 consecutive office visits

${ }^{\mathrm{b}}$ For diastolic blood pressure: treatment-emergent low $\leq 50 \mathrm{mmHg}$ with $\geq 10$ $\mathrm{mmHg}$ decrease; treatment-emergent high $\geq 90 \mathrm{mmHg}$ with $\geq 10 \mathrm{mmHg}$ increase; PCS high $\geq 105 \mathrm{mmHg}$ with $\geq 15 \mathrm{mmHg}$ increase; sustained elevation

$\geq 90 \mathrm{mmHg}$ with $\geq 10 \mathrm{mmHg}$ increase for 2 consecutive office visits

'For pulse: treatment-emergent low $<50 \mathrm{bpm}$ with $\geq 15 \mathrm{bpm}$ decrease; treatment-emergent high $>100 \mathrm{bpm}$ with $\geq 15 \mathrm{bpm}$ increase; sustained elevation $>100 \mathrm{bpm}$ with $\geq 15 \mathrm{bpm}$ increase for 2 consecutive office visits

among any galcanezumab-treated patients or placebo in either of those previous reports, or in this report.

Although the pivotal galcanezumab studies included both the $120 \mathrm{mg}$ ( $240 \mathrm{mg}$ loading dose) and $240 \mathrm{mg}$ doses administered monthly, the efficacy data in both the episodic migraine studies and the chronic migraine study consistently demonstrated the similarity across efficacy measures for both galcanezumab doses. Therefore, the approved dosage of galcanezumab is a monthly dose of $120 \mathrm{mg}$ injected subcutaneously following an initial loading dose of $240 \mathrm{mg}$.

Galcanezumab offers the convenience and adherence benefits of once monthly dosing. In clinical practice, tolerability or unsatisfactory efficacy of current migraine preventive treatments often results in non-compliance and treatment failure $[43,44]$.

The span of the current clinical studies of galcanezumab has not been long enough to answer questions of long-term safety; however, no unexpected safety issues have emerged among these data that extend out to 1 year of treatment. 
A meta-analysis of 10 randomized controlled trials of CGRP monoclonal antibodies for the prevention of episodic migraine was recently published [25]. This analysis supports the findings that CGRP monoclonal antibodies are generally safe and well tolerated. However, the metaanalysis did not include trials for the prevention of chronic migraine, which we have presented in this report for treatment with galcanezumab. In addition, other safety outcomes other than AEs were not included resulting in an incomplete presentation of the safety data in the meta-analysis. Finally, the meta-analysis only presented safety data for up to 6 months. In this report, we have presented safety and tolerability data for up to 1 year of exposure to galcanezumab and none of the safety outcomes assessed appear to increase in incidence with longer duration of treatment. Lastly there were no new AEs of concern that occurred with a treatment duration of up to 1 year.

A limitation of these integrated analyses is that rare AEs or long-term risks may not be evident in studies of shorter duration. Also, restrictions on the inclusion of patients with acute or serious CV risk or pregnant women may limit the generalizability of these results.

\section{Conclusion}

In these studies, for up to 1 year of treatment, a favorable safety and tolerability profile for galcanezumab in the prevention of episodic and chronic migraine was evident. TEAEs, including those identified as ADRs due to their potential clinical significance, were generally transient in nature, resolved, and were amenable to monitoring. The proportion of DCAEs was low across all studies providing support for the tolerability of galcanezumab in patients with migraine. In addition, the overall safety profiles of galcanezumab $120 \mathrm{mg}$ versus galcanezumab $240 \mathrm{mg}$ in the integrated double-blind studies group and all-galcanezumab exposure group were similar.

\footnotetext{
Abbreviations

ADR: Adverse drug reaction; AE: Adverse events; BP: Blood pressure CGRP: Calcitonin gene-related peptide; C-SSRS: Columbia-Suicide Severity Rating Scale; CV: Cardiovascular; DCAEs: Discontinuation due to adverse events; EAIR: Exposure adjusted incidence rates; ECG: Electrocardiogram; MedDRA ${ }^{\oplus}$ v.19.1: Medical Dictionary for Regulatory Activities; SAE: Serious adverse events; SMQs: Standard Medical Dictionary for Regulatory Activities queries; TE: Treatment-emergent; TEAEs: Treatment-emergent adverse events; ULN: Upper limit of normal
}

\section{Acknowledgements}

The authors thank Angelo Camporeale, MD, and Phebe Kemmer, PhD (Eli Lilly and Company) for review of final manuscript content. The MedDRA ${ }^{\oplus}$ trademark is registered by the International Federation of Pharmaceutical Manufacturers \& Associations on behalf of the International Council for Harmonisation of Technical Requirements for Pharmaceuticals for Human Use.

\section{Authors' contributions}

MEB, SW, TMO, and VLS conceived the study. SW led the statistical analyses. MEB, DK, SW, TMO, GMT, DM, VLS, and LY-M interpreted the data. MEB, SW,
VLS, and LY-M drafted the initial manuscript. MEB, DK, SW, TMO, GMT, DM, VLS, and LY-M contributed to revision and editing of the manuscript. MEB, DK, SW, TMO, GMT, DM, VLS, and LY-M have read and approved the manuscript. The corresponding author attests that all listed authors meet authorship criteria and that no others meeting the criteria have been omitted.

\section{Funding}

Eli Lilly and Company funded the studies in whole and its employees and assigns were involved in study design, data collection, data analysis, data interpretation, and writing of all related reports and publications. The corresponding author had full access to all study data and had final responsibility for the decision to submit for publication.

\section{Availability of data and materials}

Lilly provides access to all individual participant data collected during the trial, after anonymization, with the exception of pharmacokinetic or genetic data. Data are available to request 6 months after the indication studied has been approved in the US and EU and after primary publication acceptance, whichever is later. No expiration date of data requests is currently set once data are made available. Access is provided after a proposal has been approved by an independent review committee identified for this purpose and after receipt of a signed data sharing agreement. Data and documents, including the study protocol, statistical analysis plan, clinical study report, blank or annotated case report forms, will be provided in a secure data sharing environment. For details on submitting a request, see the instructions provided at www.vivli.org.

\section{Ethics approval and consent to participate}

This study was reviewed and approved by appropriate institutional review boards and was conducted according to the Declaration of Helsinki. All participants gave written informed consent. The ethical review boards included Quorum Review Inc., IRB Services, Montreal Neurological Institute and Hospital, Cedars Sinai Medical Center, North West - Liverpool East Research Ethics Committee, Isala Klinieken METC, Hospital Universitari Vall d'Hebron - Comité Ético de Investigación Clínica, Dean Foundation for Health Research and Education, Eticka komise IKEM a Thomayerovy nemocnice, Ethikkommission der Landesärztekammer Hessen, Comite de Etica Independiente en Invest. Clinica Dr. C Barclay, Comite de Etica del Centro de Osteopatias Medicas, Hillel Yaffe Medical Center, Rambam Medical Center, Chaim Sheba Medical, Maccabi Healthcare Services Kfar Saba ERB at Assuta Medical Center, Hallym University Dongtan Sacred Heart Hospital, Samsung Medical Center, Eulji General Hospital, Seoul National University Hospital, Korea University Guro Hospital, Kangbuk Samsung Hosp, Hallym Univ. of Medicine, Kangnam Sacred Heart Hospital, Chi-Mei Medical Center Yung Kang, Kaohsiung Medical University Chung-Ho Memorial Hospital, SinLau Hospital, Taipei Veterans General Hospital, Research Ethics Review Committee, Grupo Médico Camino S.C., Medical Care and Research, S.A. de C.V., Hospital Angeles de Culiacan, Grupo Medico Carracci, Estimulación Magnetica Transcraneal de Mexico, Baylor, Scott, \& White, West Midlands - Edgbaston REC, Comitato Etico Irccs San Raffaele Pisana, Comitato Etico Interaziendale Bologna-IMOLA, Comitato Etico Area Vasta Centro Presso AOU, Comitato Etico della Provincia di Modena, Comitato Etico Ospedale San Raffaele, Eticka komise Clintrial, s.r.o., Eticka komise FN u sv. Anny v Brne, Sanatorio Allende-Cordoba, Instituto Reumatologico Strusberg, Tel Aviv Sourasky Medical Center, Thomas Jefferson University, Crescent City institutional Review Board, Office of Research Compliance - University of South Carolina, Far Eastern Memorial Hospital Research Ethics Review Committee, Commissie Medische Ethiek Universitair Ziekenhuis Brussel, Conjoint Medical Ethics Committee, CPP Sud Mediterannée $V$, and Egeszsegugyi Tudomanyos Tanacs.

\section{Consent for publication}

Not applicable.

\section{Competing interests}

MEB, SW, TMO, LY-M, and VLS are full-time employees of Eli Lilly and Company, and minor stockholders of the sponsor of the work, Eli Lilly and Company. DK has received consultant fees from Alder and Amgen; speaker fees from Teva; grants from Eli Lilly and Company, during the conduct of the study; and grants from Amgen, Teva, Alder, Biohaven, Roche, and VM Biopharma, outside the submitted work. GMT reports personal fees from Eli Lilly and Company, Teva Pharmaceuticals, and Novartis, during the conduct of 
the study and grants from Dutch Brain Foundation, Dutch Heart Foundation, and Netherlands Organization for Scientific Research (NWO), outside the submitted work. DM reports ad hoc advisory board fees from Novartis Belgium NV and Eli Lilly Benelux. DM is also a member of the editorial board of BMC Neurology and Cephalalgia. The authors received article support from Medtronic Europe and Cefaly Technology.

\section{Author details}

'Eli Lilly and Company, Lilly Corporate Center, Indianapolis, IN 46285, USA. ${ }^{2}$ California Medical Clinic for Headache, Santa Monica, CA, USA. ${ }^{3}$ Leiden University Medical Center, Leiden, The Netherlands. ${ }^{4}$ Neurology Dept and Pain Clinic (CMTD), CHR East Belgium, Verviers, Belgium.

\section{Received: 10 September 2019 Accepted: 9 January 2020 \\ Published online: 17 January 2020}

\section{References}

1. Eftekhari S, Salvatore CA, Calamari A, et al. Differential distribution of calcitonin gene-related peptide and its receptor components in the human trigeminal ganglion. Neuroscience. 2010;169:683-96. https://doi.org/10.1016/ j.neuroscience.2010.05.016.

2. Edvinsson L, Goadsby PJ. Neuropeptides in migraine and cluster headache. Cephalalgia. 1994;14:320-7. https://doi.org/10.1046/j.1468-2982.1994 1405320.x

3. Bigal ME, Walter S, Rapoport AM. Calcitonin gene-related peptide (CGRP) and migraine current understanding and state of development. Headache. 2013;53:1230-44. https://doi.org/10.1111/head.12179.

4. Edvinsson L, Haanes KA, Warfvinge $K$, et al. CGRP as the target of new migraine therapies - successful translation from bench to clinic. Nat Rev Neurol. 2018;14:338-50. https://doi.org/10.1038/s41582-018-0003-1.

5. Cady RJ, Glenn JR, Smith KM, et al. Calcitonin gene-related peptide promotes cellular changes in trigeminal neurons and glia implicated in peripheral and central sensitization. Mol Pain. 2017;7:94-105. https://doi.org/ 10.1186/1744-8069-7-94.

6. Hirsch S, Corradini L, Just S, et al. The CGRP receptor antagonist BIBN4096BS peripherally alleviates inflammatory pain in rats. Pain. 2013;154:700-7. https://doi.org/10.1016/j.pain.2013.01.002.

7. Russell FA, King R, Smillie S-J, et al. Calcitonin gene-related peptide: physiology and pathophysiology. Physiol Rev. 2014;94:1099-142. https://doi. org/10.1152/physrev.00034.2013.

8. MaassenVanDenBrink A, Meijer J, Villalón CM, et al. Wiping out CGRP: potential cardiovascular risks. Trends Pharmacol Sci. 2016;37:779-89. https:// doi.org/10.1016/j.tips.2016.06.002.

9. Kurth T, Gaziano J, Cook NR, et al. Migraine and risk of cardiovascular disease in women. JAMA. 2006;296:283-91. https://doi.org/10.1001/jama.296. 3.283 .

10. Becker C, Brobert G, Almqvist PM, et al. Migraine and the risk of stroke, TIA, or death in the UK. Headache. 2007:47:1374-84. https://doi.org/10.1111/j. 1526-4610.2007.00937.x.

11. Le H, Tfelt-Hansen $P$, Russell MB, et al. Co-morbidity of migraine with somatic disease in a large population-based study. Cephalalgia. 2011;31:4364. https://doi.org/10.1177/0333102410373159.

12. Chen YC, Tang CH, Ng K, et al. Comorbidity profiles of chronic migraine sufferers in a national database in Taiwan. J Headache Pain. 2012;13:311-9. https://doi.org/10.1007/s10194-012-0447-4

13. Sacco S, Ornello R, Ripa P, et al. Migraine and risk of ischaemic heart disease: a systematic review and meta-analysis of observational studies. Eur J Neurol. 2015;22:1001-11. https://doi.org/10.1111/ene.12701.

14. Peng KP, Chen YT, Fuh JL, et al. Migraine and incidence of ischemic stroke: a nationwide population-based study. Cephalalgia. 2017;37:327-35. https:// doi.org/10.1177/0333102416642602.

15. Benschop RJ, Collins EC, Darling RJ, et al. Development of a novel antibody to calcitonin gene-related peptide for the treatment of osteoarthritis-related pain. Osteoarthr Cartil. 2014;22:578-85. https://doi.org/10.1016/j.joca.2014.01. 009.

16. Oakes TM, Skljarevski V, Zhang Q, et al. Safety of galcanezumab in patients with episodic migraine: a randomized placebo-controlled dose-ranging phase 2b study. Cephalalgia. 2018;38:1015-25. https://doi.org/10.1177/ 0333102417747230.

17. Dodick DW, Goadsby PJ, Spierings ELH, et al. Safety and efficacy of LY2951742, a monoclonal antibody to calcitonin gene-related peptide, for the prevention of migraine: a phase 2, randomised, double-blind, placebocontrolled study. Lancet Neurol. 2014;13:885-92. https://doi.org/10.1016/ S1474-4422(14)70128-0.

18. Skljarevski $\mathrm{V}$, Oakes TM, Zhang Q, et al. Effect of different doses of galcanezumab vs placebo for episodic migraine prevention: a randomized clinical trial. JAMA Neurol. 2018;75:187-93. https://doi.org/10.1001/ jamaneurol.2017.3859.

19. Stauffer VL, Dodick DW, Zhang Q, et al. Evaluation of galcanezumab for the prevention of episodic migraine: the EVOLVE-1 randomized clinical trial. JAMA Neurol. 2018;75:1080-8. https://doi.org/10.1001/jamaneurol.2018.1212.

20. Skljarevski V, Matharu M, Millen BA, et al. Efficacy and safety of galcanezumab for the prevention of episodic migraine: results of the EVOLVE-2 phase 3 randomized controlled clinical trial. Cephalalgia. 2018;38: 1442-54. https://doi.org/10.1177/0333102418779543.

21. Detke HC, Goadsby PJ, Wang S, et al. Galcanezumab in chronic migraine: the randomized, double-blind, placebo-controlled REGAIN study. Neurology. 2018:91:e2211-21. https://doi.org/10.1212/WNL.0000000000006640.

22. Camporeale A, Kudrow D, Sides R, et al. A phase 3, long-term, open-label safety study of Galcanezumab in patients with migraine. BMC Neurol. 2018; 18:188-99. https://doi.org/10.1186/s12883-018-1193-2.

23. Förderreuther $S$, Zhang $Q$, Stauffer $V L$, et al. Preventive effects of galcanezumab in adult patients with episodic or chronic migraine are persistent: data from the phase 3, randomized, double-blind, placebocontrolled EVOLVE-1, EVOLVE-2, and REGAIN studies. J Headache Pain. 2018; 19:121. https://doi.org/10.1186/s10194-018-0951-2.

24. Silberstein SD, Stauffer VL, Day KA, et al. Galcanezumab in episodic migraine: subgroup analyses of efficacy by high versus low frequency of migraine headaches in phase 3 studies (EVOLVE-1 \& EVOLVE-2). J Headache Pain. 2019;20:75. https://doi.org/10.1186/s10194-019-1024-x.

25. Xu D, Chen D, Zhu LN, et al. Safety and tolerability of calcitonin-generelated peptide binding monoclonal antibodies for the prevention of episodic migraine - a meta-analysis of randomized controlled trials. Cephalalgia. 2019;39:1164-79. https://doi.org/10.1177/0333102419829007.

26. Posner K, Brown GK, Stanley B, et al. The Columbia-suicide severity rating scale: initial validity and internal consistency findings from three multisite studies with adolescents and adults. Am J Psychiatry. 2011;168:1266-77. https://doi.org/10.1176/appi.ajp.2011.10111704.

27. Buse DC, Rupnow MFT, Lipton RB. Assessing and managing all aspects of migraine: migraine attacks, migraine-related functional impairment, common comorbidities, and quality of life. Mayo Clin Proc. 2009;84:422-35. https://doi.org/10.1016/S0025-6196(11)60561-2.

28. Dodick DW, Ashina M, Brandes JL, et al. ARISE: a phase 3 randomized trial of erenumab for episodic migraine. Cephalalgia. 2018;38:1026-37. https://doi. org/10.1177/0333102418759786.

29. Goadsby PJ, Reuter U, Hallstrom Y, et al. A controlled trial of erenumab for episodic migraine. N Engl J Med. 2017;377:2123-32. https://doi.org/10.1056/ NEJMoa1705848.

30. Tepper SJ, Ashina M, Reuter U, et al. Safety and efficacy of erenumab for preventive treatment of chronic migraine: a randomised, double-blind, placebo-controlled phase 2 trial. Lancet Neurol. 2017;16:425-34. https://doi. org/10.1016/S1474-4422(17)30083-2.

31. Aimovig ${ }^{\mathrm{TM}}$ (Erenumab-aooe) injection. Amgen Inc. and Novartis Pharmaceuticals Corporation. https://www.accessdata.fda.gov/drugsatfda_ docs/label/2019/761077s003lbl.pdf. Accessed 4 Aug 2019.

32. Dodick DW, Silberstein SD, Bigal ME, et al. Effect of fremanezumab compared with placebo for prevention of episodic migraine: a randomized clinical trial. JAMA. 2018;319:1999-2008. https://doi.org/10.1001/jama.2018. 4853 .

33. Silberstein SD, Aycardi E, Bigal ME, et al. Fremanezumab for the preventive treatment of chronic migraine. N Engl J Med. 2017;377:2113-22. https://doi. org/10.1056/NEJMoa1709038.

34. Ajovy $^{\mathrm{TM}}$ (fremanezumab-vfrm) injection. Teva Pharmaceuticals USA, Inc. https://www.accessdata.fda.gov/drugsatfda_docs/label/2018/761089s000lbl. pdf. Accessed 10 Jan 2018

35. Silberstein SD, McAllister $P$, Ning $X$, et al. Safety and tolerability of fremanezumab for the prevention of migraine: a pooled analysis of phases 2b and 3 clinical trials. Headache. 2019;59:880-90. https://doi.org/10.1111/ head.13534.

36. Sacco $S$, Bendtsen $L$, Ashina M, et al. European headache federation guideline on the use of monoclonal antibodies acting on the calcitonin gene related peptide or its receptor for migraine prevention. J Headache 
Pain. 2019;20(6). https://doi.org/10.1186/s10194-018-0955-y Erratum in: J Headache Pain. 2019;20:58.

37. Kaiser EA, Rea BL, Kuburas A, et al. Anti-CGRP antibodies block CGRPinduced diarrhea in mice. Neuropeptides. 2017;64:95-9.

38. Lempert T, Neuhauser $H$. Epidemiology of vertigo, migraine and vestibular migraine. J Neurol. 2009;256:333-8. https://doi.org/10.1007/s00415-0090149-2.

39. Dash AK, Panda N, Khandelwal G, et al. Migraine and audiovestibular dysfunction: is there a correlation? Otolaryngol Head Neck Surg. 2008;29: 295-9. https://doi.org/10.1016/j.amjoto.2007.09.004.

40. Kong WJ, Scholtz AW, Kammen-Jolly K, et al. Ultrastructural evaluation of calcitonin gene-related peptide immunoreactivity in the human cochlea and vestibular endorgans. Eur J Neurosci. 2002;15:487-97. https://doi.org/10. 1046/j.0953-816x.2001.01880.x.

41. Schrott-Fischer A, Kammen-Jolly K, Scholtz A, et al. Efferent neurotransmitters in the human cochlea and vestibule. Acta Otolaryngol. 2007;127:13-9. https://doi.org/10.1080/00016480600652123.

42. Regev A, Camporeale A, Skljarevski V, et al. Hepatic safety of galcanezumab in patients with migraine: results of three phase 2 double-blind placebocontrolled trials. Neurology. 2017;88(Suppl):164-8.

43. Hepp Z, Dodick D, Varon SF, et al. Adherence to oral migraine-preventive medications among patients with chronic migraine. Cephalalgia. 2015;35: 478-88. https://doi.org/10.1177/0333102414547138.

44. Loder EW, Rizzoli P. Tolerance and loss of beneficial effect during migraine prophylaxis: clinical considerations. Headache. 2011;51:1336-45. https://doi. org/10.1111/j.1526-4610.2011.01986.x.

\section{Publisher's Note}

Springer Nature remains neutral with regard to jurisdictional claims in published maps and institutional affiliations.

Ready to submit your research? Choose BMC and benefit from:

- fast, convenient online submission

- thorough peer review by experienced researchers in your field

- rapid publication on acceptance

- support for research data, including large and complex data types

- gold Open Access which fosters wider collaboration and increased citations

- maximum visibility for your research: over $100 \mathrm{M}$ website views per year

At $\mathrm{BMC}$, research is always in progress.

Learn more biomedcentral.com/submissions 